\title{
Gestational Diabetes: Haematological Perspective
}

\author{
Obeagu Emmanuel Ifeanyi1,2, Obeagu Getrude Uzoma ${ }^{3}$, Anaebo Queen Braxton N4 \\ ${ }^{1}$ Medical Laboratory Science, University Health Services, Michael Okpara University of Agriculture, Umudike, Abia State, Nigeria \\ 2Department of Medical Laboratory Science, Imo State University, Owerri, Nigeria \\ 3Department of Nursing Science, Ebonyi State University, Abakaliki, Nigeria \\ ${ }^{4}$ Department of Accident/Emergency, Lagos University Teaching Hospital, Lagos, Nigeria

\section{${ }^{*}$ Corresponding Author} \\ Obeagu Emmanuel Ifeanyi

\section{Article History} \\ Received: 10.10 .2019 \\ Accepted: 18.10 .2019 \\ Published: 21.10 .2019

\begin{abstract}
Gestational diabetes is a carbohydrate intolerance of variable severity with onset or first recognition during pregnancy. It occurs in all ages but more pronounced among the aging pregnant women. Haematological parameters have been reported as good markers to monitor the gestational diabetes patients. Careful haematological investigations will help to improve the wellbeing of the affected patients and prevent it as predictors of the severity of the disease. This paper was written to enhance the knowledge of the society on this incident that happens to a lot of pregnant women if not monitored may precipitate so many damages in the systems and organs of the pregnant women.
\end{abstract}

Keywords: Gestational diabetes, pregnant women, haematological perspective.

\section{Gestational Diabetes}

Gestational diabetes is a carbohydrate intolerance of different level of severity with onset or first presentation during pregnancy. This is linked to insufficient insulin in the aspect of insulin resistance [1]. The risk factors include overweight, previously having gestational diabetes, a family history of type 2 diabetes and having polycystic ovarian syndrome [2].

Prevention is by ensuring a healthy weight and exercising prenatally [1]. Gestational diabetes is managed with a diabetic diet, exercise, and also insulin injections. A lot of women are capable to manage their blood sugar with a diet and exercise [1]. Gestational diabetes affects $3-9 \%$ of pregnancies relative to the population studied. It is frequently seen during the last three trimester of pregnancy. It affects $1 \%$ of those under the age of 20 years and $13 \%$ of those over the age of 44 years [1].

\section{Haematological findings in gestational diabetes}

The observations of Kim et al. [3] showed that mean platelet volume (MPV), plateletcrit (PCT), platelet distribution width (PDW), white blood cell count (WBC), platelet count, platelet to lymphocyte ratio (PLR) and neutrophil to lymphocyte ratio (NLR) were different between the normal and diabetic group which was statistically significant. Levels of MPV, PCT and PDW were significantly different between the regulated HBA1c $(<7 \%)$ and unregulated HBA1c $(\geq 7 \%)$ diabetic patients and levels of these parameters tend to increase in unregulated patients. Levels of MPV in retinopathy and lymphocyte counts in nephropathy were different in patients with and without microvascular diabetic complications. Total white cell count, PDW and PLR levels were found to be independent predictor of impaired glucose regulation in diabetic patients [3].

Patients with type 2 diabetes mellitus (T2DM) have been reported to have an elevated risk of coagulation abnormalities and thromboembolic episodes. Platelets have a main function and increased adhesion, activation and aggregation of platelets due to dysregulation of several signaling pathways and metabolic alterations including insulin resistance, hyperglycaemia and dyslipidaemia have been shown in gestational diabetic patients [4]. Systemic inflammation, oxidative stress, impaired calcium metabolism, reduced bioavailability of nitric oxide, raised phosphosrylation and glycosylation of cellular proteins are involved in increased platelet activation and raised release of prothrombotic and proinflammatory agents in gestational diabetes [5]. Larger platelets which can be shown by raised MPV are more active because of increased prothrombotic contents, such as thromboxane $A_{2}$, thromboxane $B_{2}$, platelet factor 4 , serotonin and platelets derived growth factor [6].

Copyright @ 2019: This is an open-access article distributed under the terms of the Creative Commons Attribution license which permits unrestricted use, distribution, and reproduction in any medium for non commercial use (NonCommercial, or CC-BY-NC) provided the original author and source are credited. 
It has been shown that association of raised PMV with predictors, diabetes and vascular diabetic complications are reported in the study of Jabeen et al. [7]. Also, there is a link of MPV and impaired glucose regulation in diabetic patients was reported by Ozder and Eker [8]. As with MPV, raised PDW is also reported to be linked with diabetes and vascular complications [9].

Inflammation is strongly linked to both secretary function of beta cell and insulin resistance [10]. Circulatory inflammatory molecules can decrease beta cell functions directly by secretory glucotocixicity and lipotoxicity occur and causes enhanced inflammatory process and a vicious cycle [10].

Elevated WBC is a classical inflammatory marker and shows association of inflammation with impaired glucose metabolism, insulin resistance and diabetes [11].

Platelet lymphocyte ratio and neutrophil lymphocyte ratio have been introduced as novel inflammatory indicators in cardiac and non cardiac disorders. Elevated levels of PLR and NLR were stated in gestational diabetes and diabetic nephropathy [12]. Also, the thromboembolic disorders, relationships of platelet indices with inflammation, disease activity of inflammatory disorders and response to anti-inflammatory therapies have been reported.

\section{CONCLUSION}

Gestational diabetes is a serious metabolic disorder in pregnancy when it occurs. It can occur at any stage of pregnancy but occurs more at third trimester and has higher prevalent rate with increased age especially those above 44 years. It can be prevented by exercising before pregnancy and proper dieting and those with previous history of gestational diabetes and with family history of it should be monitored from the first time of antenatal visit to hospital.

The haematological parameters has been shown to been good indicators of health and diseases states [13, 14]. It has been reported that haematological variables are good markers in gestational diabetes ranging from retinopathy, diabetic nephropathy, cardiac and cardiac disorders and so many other complications of gestational diabetes. The patients should be properly monitored and managed adequately to avoid its attendant consequences that can affect both the mother and the child.

\section{REFERENCE}

1. International Diabetes Federation. (2006). The IDF consensus worldwide definition of the metabolic syndrome. IDF Communications, 1-23.

2. Donovan, J., Mcintyre, H., \& Blackorbay, M. (2010). Drugs for gestational diabetes. Australian Prescriber, 33(5): $141-144$.

3. Kim, J. H., Bae, H. Y., \& Kim, S. Y. (2014). Response: clinical marker of platelet hyperreactivity in diabetes mellitus (diabetes metab j 2013; 37: 423-8). Diabetes \& metabolism journal, 38(2), 160-161.

4. Suslova, T.E., Sitozhevskii, .V., Ogurkova, O.N., Kravchenko, E.S., Kologrivova, I.V., Anfinogenova, Y. and Kanpov, R.S. (2014). Platle haemostasis in patients with metabolic syndrome and type 2 diabetes mellitus:Cgmp-Mediated Platelet Aggregation. Front Physiology, 5: 501.

5. El Haouari, M., \& Rosado, J.A. (2008). Platelet signaling abnormalities in patients with types 2 diabetes mellitus: a review. Blood cells molecular Diagnosis, 41: 119-123.

6. Gasparayan, A.Y., Ayvazyan, L., Mikhailidis, D.P., \& Kitas, G.D. (2011). Mean platelet volume: a link between thrombosis and inflammation? Current Pharmeutical 17: 47-58.

7. Jabeen, R., Goswami, R., Awe, O., Kulkarni, A., Nguyen, E. T., Attenasio, A., .. \& Sun, J. (2013). Th9 cell development requires a BATF-regulated transcriptional network. The Journal of clinical investigation, 123(11), 4641-4653.

8. Osder, A., \& Eker, H.H. (2014). Investigation of mean platelet volume in patients with types 2 diabets mellitus and in subjects with impaired fasting glucose: a cost-effective toll in primary health care? International Journal of Clinical Medicine, 7:2292-2297.

9. Bekler, A., Ozkn, M.T., Tenekecioglu, E., Gazi, E., Yener, A.U., Temiz, A., Altun, B., Barutiu, A., Erbag, G. and Binnetoglu, E. (2014). Incraesed platelets distribution width is associated with severity of coronary artery disease in patients with acute coronary syndrome. Angiology, 66: 638-643.

10. Das, A. and Mukhopadhyay, S. (2011). The evil axis of obesity, inflammation and type 2 diabets, endocrinology and metabolic immune disorder and drug target, 11 (7):23-31.

11. Twig, G., Afek, A., Shamiss, A., Derazne, E., Tzur, D., Gordon, B., \& Tirosh, A. (2013). White blood cell count and incidence of type 2 diabetes in young men. Diabetes Care 36: 276-282.

12. Akbas, E.M., Demirtas, L., Gudu, A., Erdur, F.M., Ozcicek, F., \& Turmen, K. (2014). The emerging role of sirtuin 1,-3 and -4 in glucose and lipid metabolism and diabetes mellitus. Journal of molecular gene medicine 1:18

13. Obeagu, E.I., Obeagu, G.U., Chijioke, U.O., \& Ofor, I.B. (2017). Analysis of Alterations in Selected Haematological Parameters of Ascariasis Patients in Umudike, Abia State, Nigeria. Ann. Clin. Lab. Res. 5(3): 193.

14. Obeagu, E.I., Azuonwu, O., Didia, B.C. and Obeagu, G.U. (2018). Determination of Haematological Changes Associated with Syphilis in Subjects in Umudike, Abia State, Nigeria. Cohesive Journal of Microbiology and Infectious Disease, 1(1): 505 